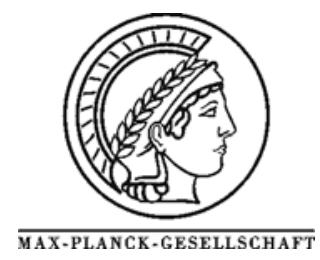

\title{
Preparation, physical characterization and catalytic properties of unsupported Pt-Rh catalyst
}

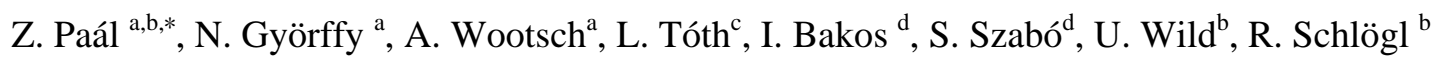 \\ ${ }^{a}$ Institute of Isotopes, Hungarian Academy of Sciences, P.O. Box 77, H-1525 Budapest, Hungary \\ ${ }^{\mathrm{b}}$ Fritz-Haber-Institut der MPG, Faradayweg 4-6, D-14195 Berlin, Germany \\ ${ }^{\mathrm{c}}$ Institute of Technical Physics and Materials Science, Hungarian Academy of Sciences, \\ P.O. Box 49, H-1525 Budapest, Hungary \\ ${ }^{\mathrm{d}}$ Institute of Materials and Environmental Chemistry, CRC, Hungarian Academy of Sciences, \\ P.O. Box 17, H-1525 Budapest, Hungary
}

*Corresponding author: e-mail paal@iki.kfki.hu,

Received 30 March 2007; revised 22 May 2007; accepted 12 June 2007 Available online 30 July 2007.

\section{Abstract}

Rh was deposited on a parent platinum black catalyst by an underpotential deposition method. Mean particle size and bulk composition of this Rh-Pt sample was determined by TEM and EDS. No individual Rh grains could be observed, but Rh was present in the near-surface regions, according to energy-filtered TEM images. The surface-sensitive cyclic voltammetry indicated $15-20 \% \mathrm{Rh}$ on the surface. XPS, in turn, detected $\sim 2-2.5 \% \mathrm{Rh}$ in the information depth. The Rh-Pt catalyst was tested in methylcyclopentane hydrogenative ring-opening reaction between 468 and $603 \mathrm{~K}$ and 8 to $64 \mathrm{kPa} \mathrm{H}_{2}$ pressure (with $1.3 \mathrm{kPa} \mathrm{MCP}$ ). The parent Pt black as well as a Rh black catalyst was also studied for comparison. MCP produced ring opening and hydrogenolysis products. The ring-opening products (ROP) consisted of 2- and 3-methylpentane (2MP and 3MP) as well as hexane $(\mathrm{nH})$. These were the main products, together with some fragments and unsaturated hydrocarbons. The amount of the latter class increased at higher temperatures. The selectivities of ROP, fragments, and benzene over Rh-Pt catalyst as a function of temperature were between the values observed on Pt and Rh. The hydrogen pressure dependence of selectivities on $\mathbf{R h}-\mathbf{P t}$ was more similar to that observed on Pt. Four subsequent treatments with $\mathrm{O}_{2}$ and $\mathrm{H}_{2}$ up to $T=673 \mathrm{~K}$ were applied on the bimetallic catalyst, followed by XPS and catalytic runs, respectively. These treatments promoted structural rearrangement, with XPS detecting less $\mathrm{Rh}$ in the near-surface region, partly as oxidized Rh after $\mathrm{O}_{2}$ treatment. The catalytic behavior became more Pt-like on these structural and composition changes. We concluded that adding a relatively small amount of Rh to Pt creates bimetallic active sites with properties different from those of its components, behaving as a true bimetallic catalyst.
\end{abstract}

Keywords: Platinum; Rhodium; Pt-Rh bimetallic catalyst; Cyclic voltammetry; XPS; Electron microscopy; Methylcyclopentane ring opening

\section{Introduction}

Several bimetallic catalysts have been the subject of research studies, and some also have found applications in practice [1,2]. Catalysts in which both components are active represent a particular class of these. Pt-Rh belongs to this class, having obtained practical applications. They are widely used for oxidation of ammonia and also in threeway catalysts (TWCs) for suppressing car exhaust emission by NO reduction and $\mathrm{CO}$ oxidation [3,4]. Hu et al. [4] reported synergism between $\mathrm{Pt}$ and $\mathrm{Rh}$ in three-way conver- sion. Rh was considered the main active component, whereas the function of Pt was assumed to prevent deactivation of Rh.

Both Pt and $\mathrm{Rh}$ are active catalysts of hydrocarbon reactions. Platinum is the best catalyst for nondegradative reactions, whereas $\mathrm{Rh}$ has a much more marked tendency for hydrogenolytic splitting of C-C bonds than Pt [5]. Nevertheless, it belongs to those metals able to selectively catalyze the hydrogenative rupture of the cyclopentane ring ("ring opening") without extensive further fragmentation and also can catalyze skeletal isomerization of alkanes [6]. 
Karpinski and Clarke [7] reported transformations of hexane on deposited Pt-Rh films. They found that the selectivity of nondegradative reactions $\left(\mathrm{C}_{5}\right.$ and $\mathrm{C}_{6}$ cyclization) decreased with increasing Rh content. Bond [8] underlined the importance of mixed PtRh sites in bimetallic catalyst.

Counter claims have been reported as far as the surface composition of Pt-Rh bimetallic system is concerned. Rhodium segregation appeared above $800 \mathrm{~K}$, whereas the reverse occurred below $800 \mathrm{~K}[1,9]$. The importance of surface energy rather than bulk thermodynamic parameters has been pointed out [9]. The surface composition also depends on the presence of adsorbates [1]. Rh was slightly enriched on the surface of $\mathrm{Pt}-\mathrm{Rh} / \mathrm{Al}_{2} \mathrm{O}_{3}$ catalysts in the presence of hydrogen, as opposed to the adsorbate-free surface, on which Pt was enriched [10]. Wang and Schmidt [11] examined Pt-Rh particles on planar amorphous $\mathrm{SiO}_{2}$ at various temperatures in air or $\mathrm{H}_{2}$. Electron microscopy and XPS both showed that the surface of the alloy particles altered by oxidation-reduction cycling. Three temperature regions were distinguished on heating the oxidized bimetallic particles. The first stage was reduction of $\mathrm{Rh}_{2} \mathrm{O}_{3}$ to $\mathrm{Rh}$ metal, the second stage was the sintering or coalescence of the tiny $\mathrm{Rh}$ crystallites into the original particles, and the third stage was the homogenization of the segregated metal particles. Similar behavior was exhibited by the three-layer model Pt/Rh2O3/Rh catalyst [12]. Three temperature regions were observed corresponding to three different systems: Pt- $\mathrm{Rh}_{2} \mathrm{O}_{3}$, bimetallic particles, and the alloy. Baraldi et al. [13] examined the changes in the surface composition of a $\mathrm{Pt}_{50} \mathrm{Rh}_{50}(100)$ alloy. Pt surface enrichment was found under slightly oxidizing conditions; under heavy oxygen doses, in turn, the surface became Rh-rich. Because $\mathrm{Rh}_{2} \mathrm{O}_{3}$ is more stable than Pt oxides [14], it may play a significant role in surface composition changes on oxidation/reduction treatments. The higher catalytic activity of easily reducible $\mathrm{Rh}$ in supported Pt-Rh has been pointed out [15]. Very small amounts of carbon impurity also influenced the surface composition of Pt-Rh [16].

Electrochemical deposition is one method of preparing disperse bimetallic catalysts [17-20]. It involves underpotential deposition of a second metal over a selected monometallic catalyst. We decided to prepare analogous bimetallic samples applying underpotential deposition for $3 \% \mathrm{Pt} / \mathrm{SiO}_{2}$ and $\mathrm{Pt}$ black as parent catalysts. The results obtained with the $\mathrm{SiO}_{2}$ supported $\mathrm{Rh}-\mathrm{Pt}$, focusing on its catalytic properties in methylcyclopentane (MCP) reactions, have been published previously [21]. The unsupported sample, the subject of the present work, can be studied more easily by several characterization methods, continuing our previous activity using unsupported metals [22-24]. Electron microscopy (EM), electrochemical [cyclic voltammetry (CV)] measurements, and electron spectroscopy (XPS) were used for physical characterization after various treatments of the unsupported Pt-Rh catalyst. Catalytic activity, the formation of C6 products versus $<$ C6 fragments, and the distribution of the C6 ring-opening products (ROPs) were monitored to get information on catalytic properties. In this way, we attempted to obtain a complex, wide-ranging characterization of the physicochemical and catalytic properties of the Pt-Rh system.

The parent catalyst was Pt black prepared by reduction of $\mathrm{H}_{2} \mathrm{PtCl}_{6}$ with aqueous hydrazine [25,26]. The lot of Pt described in previous publications was used [26,27]. Herein it is denoted as Pt when results obtained with monometallic metals are compared.

\section{Experimental}

\subsection{Catalyst preparation}

The second metal, Rh, was deposited on platinum via the ionization of preadsorbed hydrogen (a method based on the underpotential deposition of metals on foreign metal surfaces) $[18,19]$. The actual application of that method for $\mathrm{Rh}-\mathrm{Pt}$ was described earlier in detail for preparation of $\mathrm{Rh}-$ $\mathrm{Pt} / \mathrm{SiO}_{2}$ [21]. First, $0.1 \mathrm{~g}$ of Pt catalyst in the supporting electrolyte was modified with $2 \mathrm{ml}$ of deoxygenated 0.01 mol dm${ }^{-3} \mathrm{RhCl}_{3}$ solution. When the reaction of hydrogen (adsorbed on the catalyst) with rhodium ions was completed, the catalyst was washed free of rhodium ions with deoxygenated $0.2 \mathrm{~mol} \mathrm{dm}^{-3} \mathrm{HCl}$, then with triply distilled water. Finally, the wet catalyst modified with adsorbed $\mathrm{Rh}$ was dried in deoxygenated $\mathrm{N}_{2}$ gas flowing through the reactor while the reactor was warmed with an infrared lamp. This sample is designated Rh-Pt. An unsupported Rh catalyst described earlier [28] was used as reference monometallic Rh catalyst (designated $\mathbf{R h}$ ).

\subsection{Catalyst characterization}

\subsubsection{Electrochemical characterization}

$\mathrm{CV}$ of the catalysts was done at room temperature in a three-compartment electrochemical cell using $0.5 \mathrm{~mol}$ $\mathrm{dm}^{-3}$ of electrolyte. A more detailed description of the procedure was provided in our earlier paper [26]. The upper section of the voltammogram (anodic branch, above the abscissa) corresponds to oxidative processes, whereas the reverse (reductive) processes appear on the cathodic branch, below the abscissa.

\subsubsection{XPS}

Surface composition was determined by XPS. A Leybold LHS 12 MCD instrument with a MgKa anode for XPS (pass energy, PE $=48 \mathrm{eV}$ ) was used, as reported earlier $[23,29,30]$. The binding energy (BE) was calibrated to the Au $4 f_{7 / 2}$ line $(B E=84.0 \mathrm{eV})$. The work function with a purified sample (after $\mathrm{H}_{2}$ treatment) was $5.2 \mathrm{eV}$, in good agreement with value of $5.1 \mathrm{eV}$ reported for an analogous Pt sample [31]. Atomic compositions were determined using the SciPlot spectrum evaluation program (৫M. Wesemann, Berlin) and applying literature sensitivity factors 
Table 1: Comparison of the surface composition of the Rh-Pt catalysts measured by XPS in the "as is" state and after treatments

\begin{tabular}{|c|c|c|c|c|c|c|c|}
\hline & \multicolumn{7}{|c|}{ Pretreatments } \\
\hline & As is & $\mathbf{H}_{2}, 300 \mathrm{~K}$ & $\mathrm{LTH}_{2}$ & $\mathrm{O}_{2}$ & $\mathrm{MTH}_{2}$ & & $\mathrm{HTH}_{2}$ \\
\hline Rh 3d & 1.1 & 1.4 & 1.4 & 1.5 & 0.9 & - & 1.0 \\
\hline Rh 3p & - & - & - & - & - & 0.7 & - \\
\hline 0 1s & 25.9 & 9.5 & 8.9 & 28.7 & 12.4 & 12.4 & 10.3 \\
\hline C 1s & 24.2 & 27.8 & 20.7 & 9.5 & 20.9 & 21.0 & 16.0 \\
\hline Pt $4 \mathrm{f}$ & 48.8 & 61.3 & 69.0 & 60.3 & 65.8 & 65.9 & 72.7 \\
\hline $\mathbf{R h}^{\mathbf{a}}$ & 2.2 & 2.3 & 2.0 & 2.4 & 1.3 & 1.1 & 1.3 \\
\hline $\mathbf{P t}^{\mathrm{a}}$ & 97.8 & 97.7 & 98 & 97.6 & 98.7 & 98.9 & 98.7 \\
\hline
\end{tabular}

[32]. The samples were treated in the preparation chamber of the spectrometer with $\mathrm{O}_{2}$ and $\mathrm{H}_{2}$, respectively, avoiding the contact of the sample with air between various handling procedures. The catalyst was measured in the "as is" state and after $\mathrm{H}_{2}$ treatment at $300 \mathrm{~K}$. The treatments described in detail in Section 2.2.4 were carried out under "quasi-in situ” conditions here as well, followed by XPS measurements.

The quantitative evaluation was not easy, due to the relatively small amounts of $\mathrm{Rh}$, because all $\mathrm{Rh}$ peaks are close to some of the Pt peaks. The weak Rh $5 \mathrm{~d}$ peak (at $\sim 50 \mathrm{eV}$ ) was completely suppressed by the satellite of the most intensive $\mathrm{Pt} 4 \mathrm{f}_{7 / 2}$ peak. Rh $3 \mathrm{~d}_{5 / 2}$ appeared at the lower $\mathrm{BE}$ end of Pt $3 \mathrm{~d}$, close to $\mathrm{C} 1 \mathrm{~s}$. Rh $3 \mathrm{p}_{3 / 2}$ was on the side of Pt $4 p$, which, in turn, was rather close to O 1s. Shirley background subtraction could be applied for the Pt, C, and O components, whereas the Bezier background had to be subtracted when calculating the smaller Rh peaks positioned on the side of larger Pt peaks. A simultaneous evaluation of the Pt $3 \mathrm{~d}_{3 / 2}$ and $\mathrm{Rh} 3 \mathrm{~d}$ peaks [15] was not possible in the presence of the great Pt excess. The less noisy $\mathrm{Rh} 3 \mathrm{~d}_{3 / 2}$ peak was selected for quantitative evaluation. The results were in rather fair agreement with those obtained with the use of (noisier) $\mathrm{Rh} 3 \mathrm{p}_{3 / 2}$ (as shown for one case in Table 1). This peak could not be evaluated when $\mathrm{Rh}$ was oxidized, because it was suppressed by the larger Pt 4p line. Repeated measurements after installation of a new probe produced practically identical XP spectra.

\subsubsection{Transmission electron microscopy}

TEM was used to estimate the particle shape and size and provide information on their composition. The catalyst samples were ground in an agate mortar, then dispersed in ethanol and dropped onto a holey carbon grid. Conventional TEM studies were done using a Philips CM20 electron microscope at a $200-\mathrm{kV}$ accelerating voltage. This microscope was capable of carrying out energy-dispersive $\mathrm{X}$-ray spectrometry (EDS) analysis on thin specimens with the attached X-ray detector. A high-resolution electron microscope (JEOL 3010, working at $300 \mathrm{kV}$ and supplemented with a GATAN Tridiem energy filter) also was applied for high-resolution imaging. This equipment is suitable for acquiring images using electrons of specific energy losses (energy-filtered TEM [EFTEM]), creating the so-called "elemental maps" (with a resolution of a few $\mathrm{nm}$ ). The Rh M edge was used for elemental mapping with three energy windows of $30 \mathrm{eV}$ each, centered at $332 \mathrm{eV}$ (postedge), $257 \mathrm{eV}$ (preedge 1), and $287 \mathrm{eV}$ (preedge 2).

\subsubsection{Catalytic tests and pretreatments}

MCP was reacted in a closed-loop glass reactor in the presence of excess hydrogen. A CP 9001 gas chromatograph with a 50-m CP-Sil 5CB capillary column and flame ionization detector was used for product analysis [21,33]. Samples of the Pt (23 mg), Rh-Pt (14 mg), and Rh (9 mg) catalysts were placed into the reactor. A standard MCP pressure of $1.3 \mathrm{kPa}$ was used, and the hydrogen pressure was varied between 8 and $64 \mathrm{kPa}$. The reaction temperatures ranged from 468 to $603 \mathrm{~K}$. The bimetallic $\mathbf{R h}-\mathbf{P t}$ sample could be measured between 468 and $603 \mathrm{~K}$, whereas $\mathbf{R h}$ could be tested only up to $513 \mathrm{~K}$ because of its excessive fragmentation activity at higher temperatures. Pt showed rather low activity below $513 \mathrm{~K}$. The sampling was done after $5 \mathrm{~min}$, and each run was followed by regeneration with $\mathrm{O}_{2}(6.6 \mathrm{kPa}, 2 \mathrm{~min})$ and $\mathrm{H}_{2}(20 \mathrm{kPa}, 3 \mathrm{~min})$ at the temperature of the preceding run.

The specific surface for Pt was $2.64 \mathrm{~m} 2 \mathrm{~g}-1$ (BET, $\mathrm{N}_{2}$ adsorption) [30]. The dispersion $D=0.9 \%$ ) was measured by $\mathrm{H}_{2}$ chemisorption and was used for calculation of turnover frequencies (TOFs) [27]. Adding $\mathrm{Rh}$ did not change the number of catalytically active sites on Pt; therefore, the same value was used for Rh-Pt. Classical $\mathrm{H}_{2}$ chemisorption reportedly showed the same values for $\mathrm{Pt}$ and $\mathrm{Rh}$ in a bimetallic sample [34], with CO adsorbed on pure Pt and Pt-Rh alloy as detected by infrared spectroscopy. The dispersion of $\mathbf{R h}$ sample was also $D=1 \%$ [28].

The Rh-Pt catalyst was also tested after particular $\mathrm{H}_{2}$ and $\mathrm{O}_{2}$ treatments at different temperatures, as follows:

$\mathbf{L T H}_{2}$ : as prepared, after reduction in $20 \mathrm{kPa} \mathrm{H}_{2}$ at $473 \mathrm{~K}$ for $30 \mathrm{~min}$;

$\mathbf{O}_{2}$ : pretreatment with air (13.3 $\left.\mathrm{kPa}\right)$ at $573 \mathrm{~K}$ for 20 $\min$;

$\mathbf{M T H}_{2}$ : pretreatment with $\mathrm{H} 2(26.6 \mathrm{kPa})$ at $603 \mathrm{~K}$ for $30 \mathrm{~min}$;

$\mathbf{H T H}_{2}$ : pretreatment with $\mathrm{H}_{2}(26.6 \mathrm{kPa})$ at $673 \mathrm{~K}$ for $30 \mathrm{~min}$. The catalyst was cooled in vacuum to the lowest reaction temperature after each pretreatment, and test runs were carried out with $1.3 \mathrm{kPa} \mathrm{MCP}$ plus $16 \mathrm{kPa} \mathrm{H}_{2}$ and at increasingly higher reaction temperatures. The end temperature of catalytic runs after $\mathbf{L T H}_{2}$ and $\mathbf{O}_{2}$ treatments was never higher than the subsequent pretreatment temperature. 


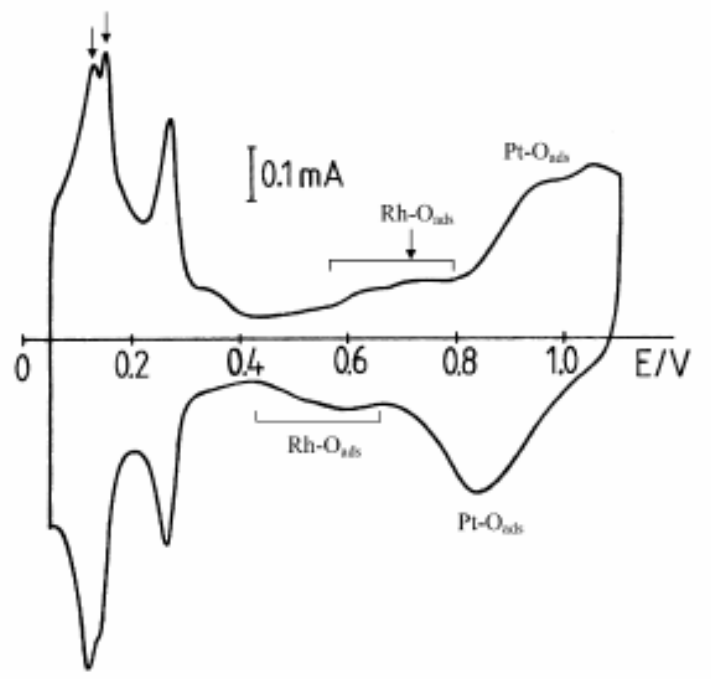

Figure 1: Cyclic voltammogram of the $\mathbf{R h}-\mathbf{P t}$ catalyst after its preparation. The double peak at $\sim 150 \mathrm{mV}$, the appearance of the adsorption of oxygenates (OH and/or $\mathrm{O}$ ) at $\sim 0.6 \mathrm{eV}$ and the peaks on the cathodic polarization indicate the presence of $\mathrm{Rh}$.

\section{Results and discussion}

\subsection{Catalyst characterization}

\subsubsection{Electrochemical characterization}

Fig. 1 shows the CV results for the platinum catalyst modified with rhodium, deposited via the ionization of the preadsorbed hydrogen. The regions of hydrogen adsorption/desorption and oxygen adsorption/desorption are characteristic of Rh and Pt. This voltammogram can be used for qualitative analysis, considering the voltammogram of our bare Pt catalyst (Fig. 2 in Ref. [26]) and the very detailed voltammograms of Rh-Pt surfaces with different compositions [20].

The first sign of the presence of $\mathrm{Rh}$ is that the first hydrogen desorption peak at 140-150 $\mathrm{mV}$ potential is a doublet, denoted by double arrows. The peak appearing at lowest potential corresponds to desorption of hydrogen from Rh. Hydrogen desorption from Pt appeared next to it, at somewhat higher potential. The second and a more pronounced effect of the presence of surface rhodium atoms is that in the course of anodic polarization the oxygen adsorption commences at lower potential (i.e., at 0.5-0.6 V). This is the peculiarity of Rh surfaces: adsorption of oxygenates $(\mathrm{OH}$ and/or $\mathrm{O})$ on platinum would start at about $0.8 \mathrm{~V}$. In the cathodic branch of the $\mathrm{CV}$, the two broad peaks at $\sim 0.85$ and $\sim 0.6 \mathrm{~V}$ can be assigned to the reductive desorption of $\mathrm{O}$ and/or $\mathrm{OH}$ from the platinum and rhodium surfaces, respectively. The separation of peaks representing the formation of $\mathrm{Pt}-\mathrm{H}_{\mathrm{ads}}$ and $\mathrm{Rh}-\mathrm{H}_{\mathrm{ads}}$ is poorer than those denoting their decomposition on the anodic branch. On the basis of analogous voltammograms [20], it seems a reasonable estimation that after the electrochemical

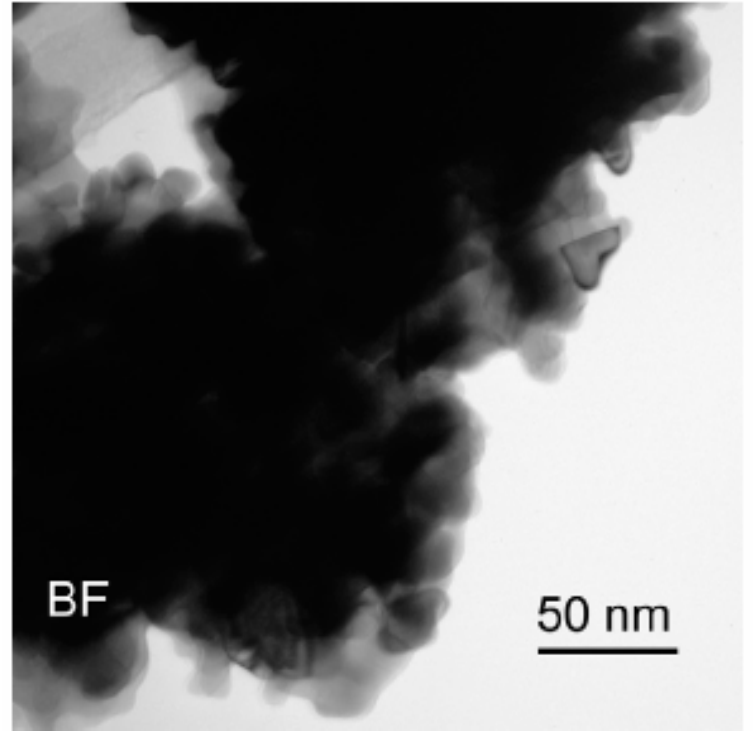

(a)

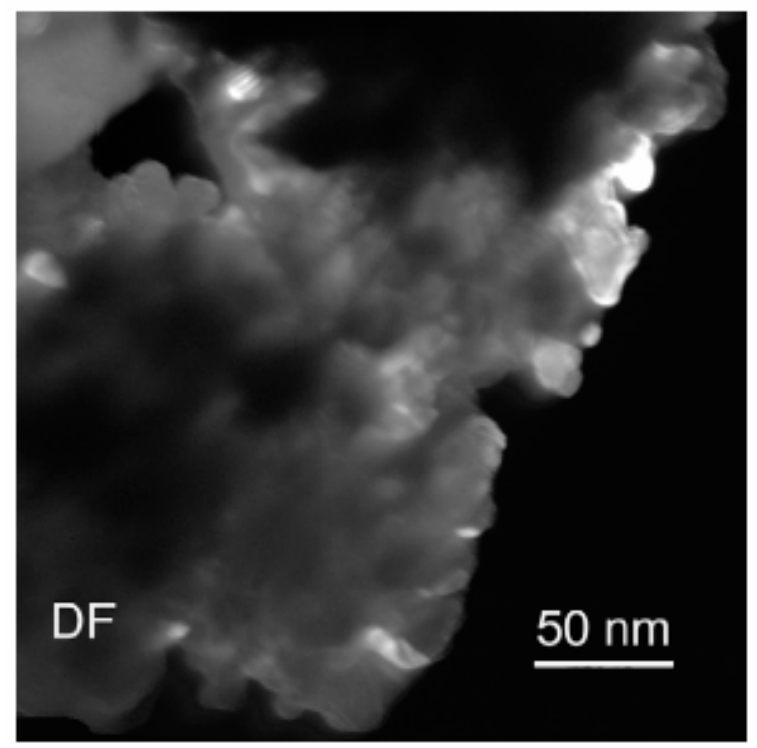

Figure 2: Bright field (a) and dark field (b) electron micrographs of $\mathbf{R h}-\mathbf{P t}$ powders in the "as prepared" state.

catalyst modification, rhodium atoms covered about 15$20 \%$ of the platinum surface.

\subsubsection{Electron microscopy}

The crystallites of unsupported Pt-Rh catalyst tend to agglomerate despite ultrasonic agitation applied during specimen preparation. Hardly any individual grains can be distinguished in the bright-field image (Fig. 2a). Some elongated "rounded needle"-shaped offshoots—reported for the parent Pt black [26]—were still present. The dark-field TEM image (Fig. 2b) shows the presence of individual crystallites within the agglomerate. Their size can be estimated as $10-15 \mathrm{~nm}$, but their number in the figure (and also in similar images) is insufficient to establish an exact statistics for particle distribution. The electron diffraction (ED) pattern shows face-centered cubic (fcc) lattice that can 


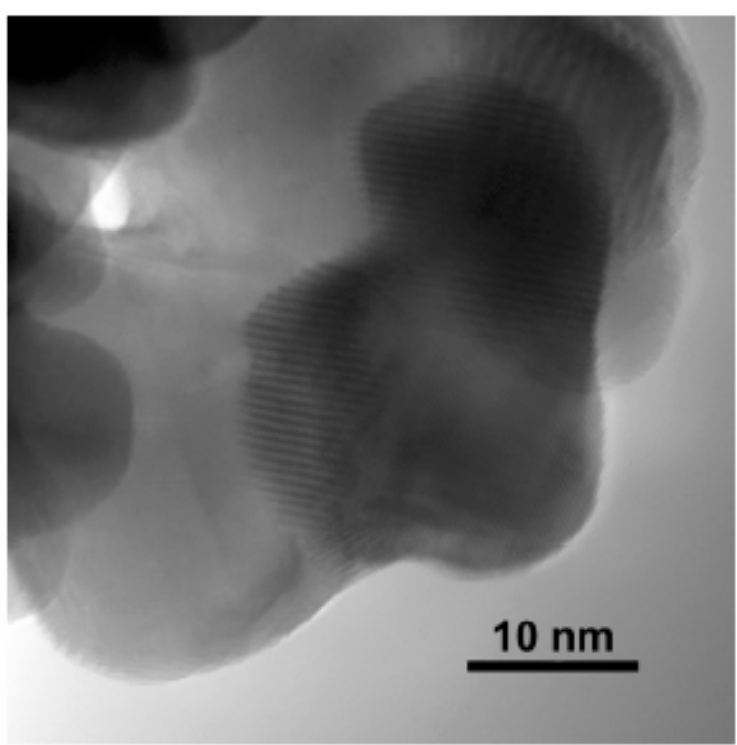

(a)

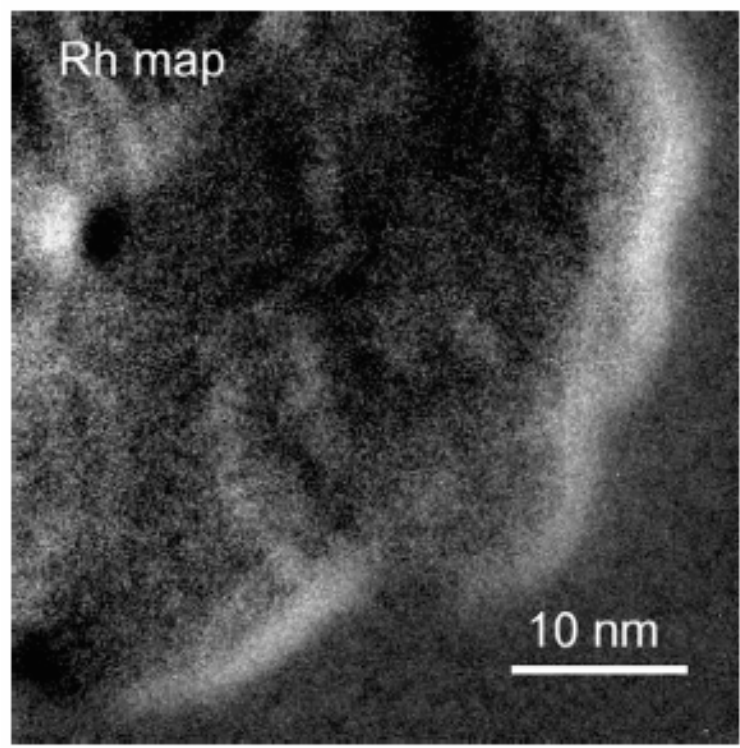

(b)

Figure 3: (a) HRTEM image of bimetallic catalyst. (b) Rh map of the same area (bright streaks) taken from EELS measurement.

belong to either $\mathrm{Rh}$ or Pt (as well as to their solid solution). These phases cannot be distinguished, with Pt and Rh both having fcc crystal structure and similar-sized elementary cells.

The high-magnification micrograph (Fig. 3a) obtained by the $300 \mathrm{kV}$ JEOL microscope using zero-loss electrons (zero-loss image [ZLI]) shows lattice fringes within the rounded grains. The TEM figure shows particles with grain sizes of 15-20 nm, slightly larger than the average particle size estimated from the BET area and dispersion value ( $10 \mathrm{~nm}$ ). Nevertheless, smaller particles may be present in regions not shown by TEM. The fringe contrast appears as Moiré patterns resulting from the interference of overlapping particles of differing crystalline orientations. A careful study of higher-magnification EM pictures reveals the presence of Pt lattices $\{111\}$ (0.227 $\mathrm{nm}$, the darker particle just above the $\mathrm{nm}$ bar) and $\{200\}$

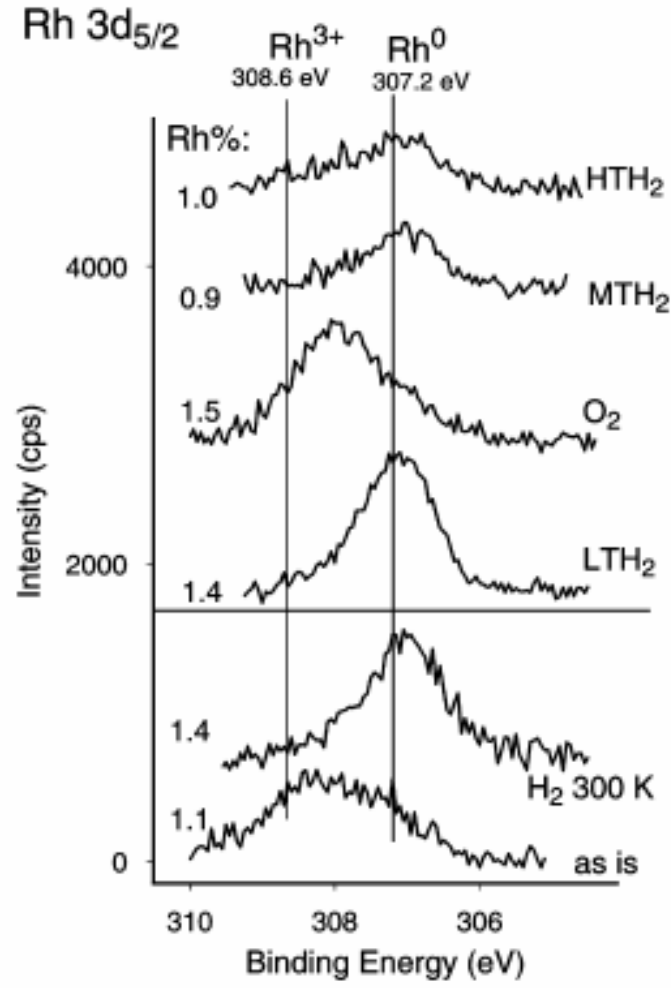

Figure 4: Rh 3d XP spectra for $\mathbf{R h - P t}$ catalyst after pretreatments.

$(0.196 \mathrm{~nm}$, the lightergray particle in the lower-left corner). No Rh grains can be seen in the filtered TEM images (elemental maps; Fig. 3b), and the assumption that no Rh 3D particles are present seems justified. Rh either can be dissolved in Pt crystallites (the equilibrium phase diagram [35] indicates complete miscibility) or can form Rh-rich regions on their surface. Fig. $3 b$ depicts the Rh elemental map of the area seen in Fig. 3a. Rh-rich areas appear as lighter patches, mainly close to grain boundaries. The contours of the particles shown in Fig. 3a can be recognized. The interparticle hole in the middle of the left-hand side appears as a black spot in Fig. 3b, and its neighbor on the left appears as two overlapping particles, obviously each rich in Rh. Note that the micrographs are two-dimensional images of threedimensional structures. The particles appearing seem to be rounded; thus, the curved fringe regions are seen almost tangentially. In this way, the image indicates enrichment of the surface component, because of this geometric artifact, as discussed in one of our earlier work (cf. Fig. 6 in Ref. [36]).

\subsubsection{XPS}

XPS proved very useful for studying the composition and valence state of the components in bimetallic catalysts [37,38]. The untreated Rh-Pt contained much oxygen and carbon impurities (Table 1). As for the ratio of these two metals, XPS showed much less Rh than could be estimated on the basis of the CV study. The different depth of information must be considered here, because $\mathrm{CV}$ is very sur 


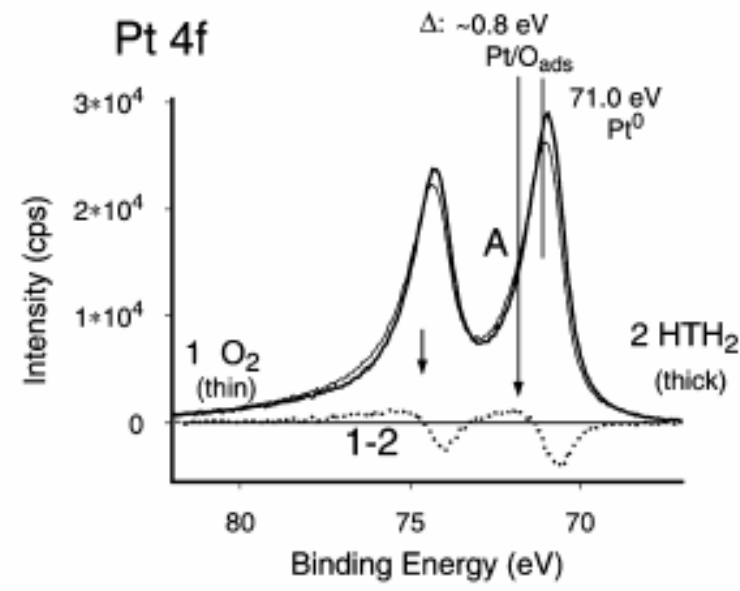

(a)

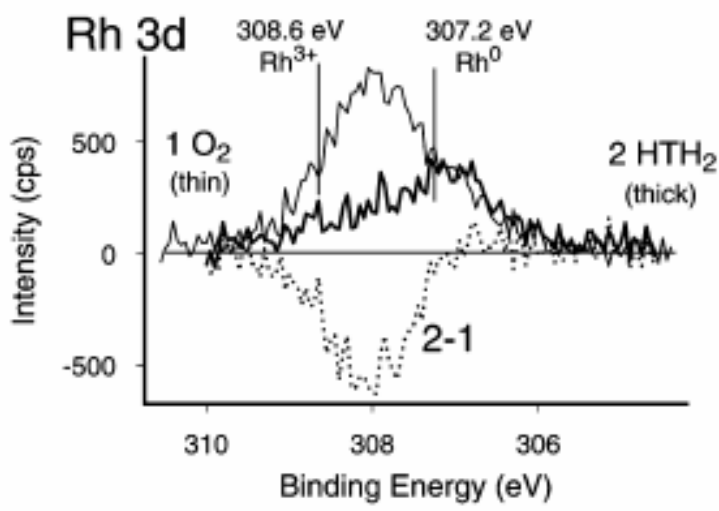

(b)

Figure 5: XP spectra of the Pt and Rh components after $\mathrm{O}_{2}$ treatment at $573 \mathrm{~K}$ and $\mathrm{H}_{2}$ treatment at $673 \mathrm{~K}$, together with the difference spectra.

face-sensitive. Some Rh-rich surface sites may be inside the agglomerates, shielded from the exciting X-ray beam [36].

The Pt $4 \mathrm{f}$ peaks indicate the presence of rather clean metallic Pt, as observed earlier after similar treatments in the case of Pt black [25,31]. Table 1 shows that treatments with $\mathrm{H}_{2}$ at even at $300 \mathrm{~K}$ reduced the samples but were less effective in removing $\mathrm{C}$ impurities. $\mathrm{O}_{2}$, in turn, was efficient in removing $\mathrm{C}$, as was also found for monometallic $\mathrm{Pt}$ $[23,25,26]$. The determination of a low percentage of $\mathrm{Rh}$ could not be very precise (due, e.g., to scattering points, background subtraction errors, etc., in lowintensity peaks). Table 1 indicates ca. $2 \% \mathrm{Rh}$ (assuming $\mathrm{Pt}+\mathrm{Rh}=100 \%$ ) in the first four cases (low-temperature $\mathrm{H}_{2}$ and $\mathrm{O}_{2}$ treatments). Less Rh was detected on subsequent $\mathrm{H}_{2}$ treatments (see below).

Fig. 4 illustrates the chemical state of Rh. Most of it appears in the oxidized state, close to $\mathrm{Rh}^{3^{+}}$, in the "as is" sample. Contacting it with $\mathrm{H}_{2}$ even at room temperature reduced the $\mathrm{Rh}$ almost entirely to Rh0. The four subsequent treatments show rather marked changes in terms of valence state. $\mathrm{O}_{2}$ at $573 \mathrm{~K}$ oxidized most of the Rh, mostly present as $\mathrm{Rh} n+$ where $n<3$. Thus, the state of "pure" $\mathrm{Rh}_{2} \mathrm{O}_{3}$ was not reached in the depth of information of our system. The peak component of $\mathrm{Rh}^{3+}$ at ca. $308.6 \mathrm{eV}$ was marked in the

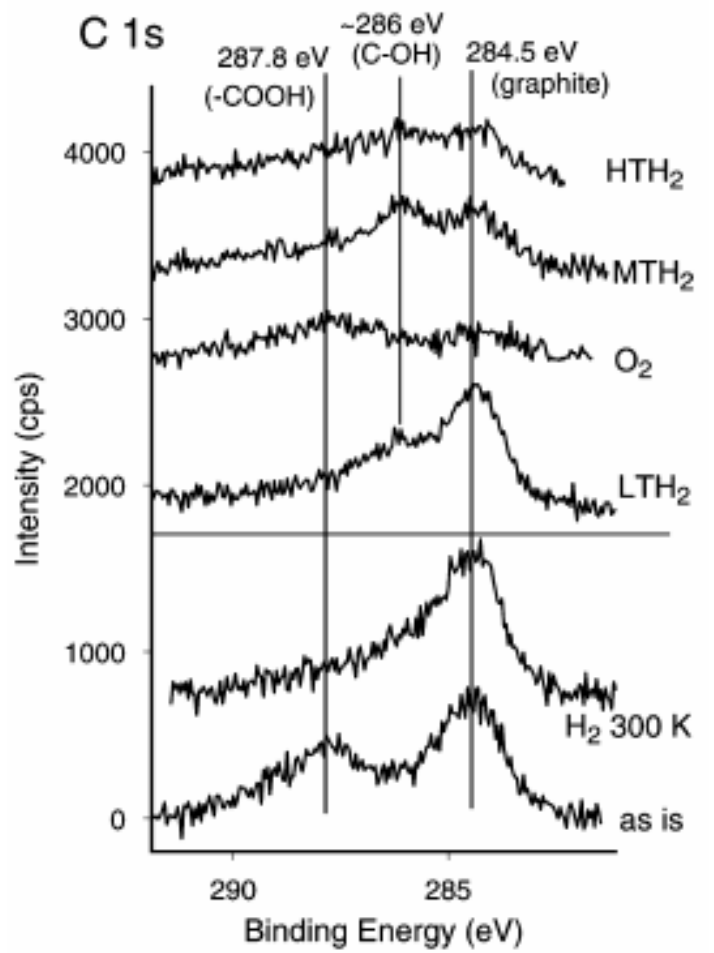

Figure 6: C 1s XP spectra for bimetallic sample in the "as is" state and after pretreatments.

$\mathrm{Rh} 3 d$ peaks of oxygen- treated $\mathrm{PtRh} / \mathrm{SiO}_{2}$ particles (with $\sim 50 \% \mathrm{Pt}$ and Rh) [11].

The effects of $\mathbf{O}_{2}$ and $\mathbf{H T H}_{\mathbf{2}}$ treatments are compared in Fig. 5. The upper panel shows that just a small amount of surface PtO appeared in the Pt $4 \mathrm{f}$ doublet on oxygen treatment at $573 \mathrm{~K}[39,40]$. This represented mainly an "adsorbed oxygen" ( $\mathrm{BE} \sim 0.8 \mathrm{eV}$ ) with just traces of $\mathrm{PtO}(\mathrm{BE} \sim 2.4 \mathrm{eV})$ [41]. Reduction of Rh by $\mathrm{H}_{2}$ resulted in the disappearance of some $\mathrm{Rh}$ from the information depth of XPS, equivalent to the amount of oxidized $\mathrm{Rh}$ after $\mathrm{O}_{2}$ treatment (Fig. 5b). This means that reduction of $\mathrm{Rh}$ was accompanied by its dissolution in bulk Pt. The area of the Rh peak, which was in metallic state even after $\mathrm{O}_{2}$ treatment, remained the same on reduction.

The carbon impurity corresponded to the hardly removable "adventitious carbon" observed after most treatments on Pt black [23,26]. The C 1s peak (Fig. 6) contained some graphitelike component plus a peak of nearly the similar intensity corresponding to carboxylic groups in the “as is" sample. $\mathrm{H}_{2}$ greatly reduced this latter component, but the overall $\mathrm{C}$ content increased [25]. Some $\mathrm{C}-\mathrm{OH}$ groups appeared after various $\mathrm{H}_{2}$ treatments as one of the possible products of the reaction of hydrogen and oxygen. Oxygen removed most carbon but carboxylic carbon reappeared. Subsequent $\mathrm{H}_{2}$ treatments increased somewhat the amount of surface carbon. An analogous phenomenon was observed on monometallic Pt black [25,30], indicating a solid-state transformation bringing out some subsurface carbon to the surface that contained both graphitic and slightly oxidized C (with single $\mathrm{C}-\mathrm{O}$ bonds). The presence 

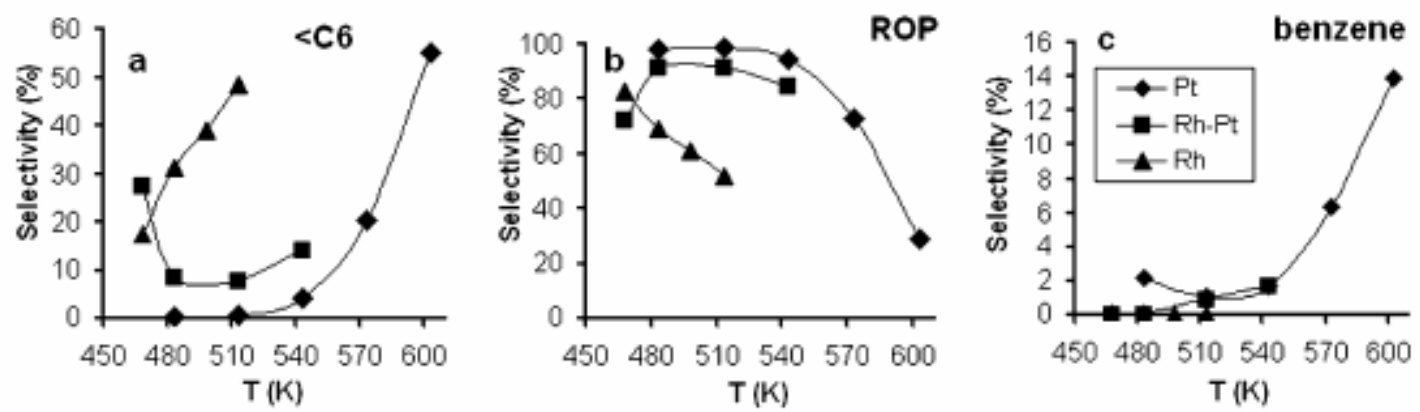

Figure 7: Selectivity of fragments (a), ring opening products (b), and benzene (c) in MCP transformation on Pt, Rh-Pt, and Rh sample at $p(\mathrm{MCP}): p(\mathrm{H} 2)=1.3: 16 \mathrm{kPa}, t=5 \mathrm{~min}$.

Table 2. Temperature dependence of the conversion of MCP over Pt, Rh-Pt, and Rh catalysts. $p(\mathrm{MCP}): p\left(\mathrm{H}_{2}\right)=$ $1.3: 16 \mathrm{kPa}$

\begin{tabular}{|c|c|c|c|c|c|c|}
\hline \multirow[b]{2}{*}{ Catalyst } & \multicolumn{3}{|c|}{ Conversion $(\%)$} & \multicolumn{3}{|c|}{$\operatorname{TOF}(1 / \mathrm{h})$} \\
\hline & Pt & $\mathbf{R h}-\mathbf{P t}$ & $\mathbf{R h}$ & $\mathbf{P t}$ & $\mathbf{R h}-\mathbf{P t}$ & $\mathbf{R h}$ \\
\hline \multicolumn{7}{|c|}{ Temperature (K) } \\
\hline 468 & & 0.4 & 3.0 & & 5.4 & 17.3 \\
\hline 483 & 0.9 & 0.7 & 2.0 & 8.5 & 11.4 & 11.6 \\
\hline 498 & & & 2.9 & & & 16.8 \\
\hline 513 & 1.9 & 0.8 & 2.6 & 17.9 & 12.1 & 15.0 \\
\hline 543 & 3.3 & 0.7 & & 31.2 & 10.6 & \\
\hline 573 & 2.0 & & & 19.3 & & \\
\hline 603 & 1.4 & & & 13.7 & & \\
\hline
\end{tabular}

of aliphatic polymer (at intermediate BE values) is not excluded either [26,42]. Pt-C species are not typical here.

\subsection{Catalytic reactions of $M C P$}

\subsubsection{Effects of reaction temperature}

The $\mathbf{R h}-\mathbf{P t}$ catalyst consists mainly of platinum, containing $\mathrm{Rh}$ islands of various sizes on its surface. Based on results of CV, XPS, and EM, the presence of Pt-rich and Rh-rich patches can be assumed, with mixed Rh-Pt sites also present, especially after hydrogen treatments. This catalyst was compared with the parent Pt black and Rh black [28].

Table 2 shows conversion values as a function of the reaction temperature at a selected hydrogen pressure, 16 $\mathrm{kPa}$, obtained without any specific treatments of the catalysts. Under these conditions, the conversion had a maximum value at $543 \mathrm{~K}$ on Pt, whereas the conversion values over $\mathbf{R h}$ were slightly higher and showed much less pronounced temperature dependence [43]. The overall activity of bimetallic catalyst was much lower than the two monometallic ones. Table 2 gives good evidence that the temperature ranges allowing evaluation are different for the three catalysts.

The conversion of MCP over pure Rh showed a very slight temperature dependence ( $E \mathrm{a} \approx 8 \mathrm{~kJ} / \mathrm{mol}$ [44]). A similar phenomenon was found on $\mathrm{Rh}-\mathrm{Pt} / \mathrm{SiO}_{2}$ [21] and $\mathrm{Ge}-\mathrm{Rh} / \mathrm{Al}_{2} \mathrm{O}_{3}$ [45]. Table 2 confirms these results. Bond [46] pointed out that the overall apparent activation energy
Table 3: Conversion of MCP on Pt, Rh-Pt and $\mathbf{R h}$ as a function of hydrogen pressure at a selected temperature ( $T$ $=513 \mathrm{~K})$

\begin{tabular}{lllr}
\hline & \multicolumn{2}{l}{ Conversion $(\%)$} \\
\cline { 2 - 4 } Catalyst & $\mathbf{P t}$ & $\mathbf{R h}-\mathbf{P t}$ & $\mathbf{R h}$ \\
\hline$p\left(\mathrm{H}_{2}\right)(\mathrm{kPa})$ & & & \\
8 & 0.7 & 0.7 & 2.6 \\
16 & 1.7 & 1.7 & 5.2 \\
32 & 3.8 & 3.6 & 10.6 \\
48 & 4.3 & 3.8 & 14.4 \\
64 & 4.5 & 2.9 & \\
\hline
\end{tabular}

depends strongly on the hydrogen reaction order of the overall reaction, as well as that of individual processes. This effect is discussed in the next section. The low activation energy also can be related to the deactivation by coke formation at higher temperature [23,25]. However, the surface state under these conditions is reproducible, as confirmed earlier by repeated reactions on Pt black [25].

\subsubsection{Response to hydrogen pressure changes}

The hydrogen pressure dependence was compared at $513 \mathrm{~K}$, a temperature at which comparable conversions were observed over all three catalysts (Table 3). The overall activity data show that we were in the positive hydrogen order range [27,47] over all samples. Rh showed much higher hydrogen pressure sensitivity at this temperature (Table 3). Rh-Pt was more Ptlike as far as hydrogen pressure dependence is concerned. In this positive hydrogen order range, the apparent activation energy was fairly low due to the Temkin equation [48]: Eapp $=E a+n i \_H i$, where $n i$ is the reaction order and $\_H i$ is the enthalpy of adsorption of reactant $i$ (which is in fact negative). In earlier work, we reported more detailed considerations for Pt black [27] and Rh catalysts [45].

The selectivity values provide additional information. Products were classified as ROPs $(n \mathrm{H}, 2 \mathrm{MP}$, and 3MP), fragments (<C6), benzene, and olefins [49]. Methylcyclopent- 1-ene (1-MCP=) represented the main unsaturated component [50], with a few other hexenes, the amounts of which were lower than that of $1-\mathrm{MCP}=$ by at least an order of magnitude. Earlier, up to 95\% ROP was reported on Pt black and $\mathrm{Pt} / \mathrm{SiO}_{2}$ at $603 \mathrm{~K}$. At low $\mathrm{p}\left(\mathrm{H}_{2}\right)$, up 
to $~ 70 \%$ of $1-\mathrm{MCP}=$ was detected [51]. More ROP was reported on supported Rh catalysts than over Pt [43]; the latter also produced benzene. Fig. 7 shows selectivity values as a function of temperature at $p(\mathrm{MCP}): p\left(\mathrm{H}_{2}\right)=1.3: 16$ $\mathrm{kPa}$. The more marked $\mathrm{C}-\mathrm{C}$ bond cleavage on $\mathbf{R h}$ [6] is obvious. The selectivity of ROP, fragments, and benzene over $\mathbf{R h}-\mathbf{P t}$ was between the values observed on $\mathbf{P t}$ and $\mathbf{R h}$ but closer to those on Pt. The pronounced increase of benzene selectivity above $540 \mathrm{~K}$ may be attributed to thermodynamics favoring aromatics at higher temperatures [52]. The high values of the ROP and $<\mathrm{C}_{6}$ selectivities after $\mathbf{L T H}_{2}$ at 468 and $483 \mathrm{~K}$ in Fig. 7 are discussed in Section 3.2.3.

Gault et al. [53] postulated "selective" and "nonselective" pathways of C5 ring opening. The latter would produce a statistical distribution of 2MP, 3MP, and $\mathrm{nH}$, whereas much less (or even zero) $n \mathrm{H}$ would be produced in the "selective" ring opening. Selective ring opening is typical for unsupported metal catalysts [6,43,49,51], with $2 \mathrm{MP} / \mathrm{nH}$ ratios increasing up to ca. $30[49,51,54]$. Lower values have been reported for supported metals [51,55], due to the postulated nonselective ring opening at metalsupport "adlineation" sites [56]. The $2 \mathrm{MP} / \mathrm{nH}$ ratios were smaller on $\mathrm{Pt}$ at low $p\left(\mathrm{H}_{2}\right)[51,55]$, whereas the reverse was reported for $\mathrm{Rh} / \mathrm{Al}_{2} \mathrm{O}_{3}$ reduced at $973 \mathrm{~K}$ [44], likely due to the adlineation effect.

The ratio of ROP-s (2MP/3MP, 2MP/nH) indicates a predominant "selective" ring opening at each temperature (Table 5). The $2 \mathrm{MP} / \mathrm{nH}$ ratio could be measured only after $\mathbf{H T H}_{\mathbf{2}}$ treatment over $\mathbf{R h}-\mathbf{P t}$, because the concentration of $\mathrm{nH}$ was below the detection limit in other runs. The ratio of 2MP and 3MP over bimetallic catalyst shows a Pt-like character, with values (between 3 and 1.5) decreasing monotonically with increasing temperature, whereas these values seem to be temperatureindependent on pure $\mathbf{R h}$. The $2 \mathrm{MP} / \mathrm{nH}$ ratio on $\mathbf{R h}-\mathbf{P t}$ has a maximum at $513 \mathrm{~K}$, whereas the ratio continuously decreases with increasing temperature on pure metals, with Pt exhibiting highest selectivity. This may correspond to the aforementioned hydrogen effects $[51,55]$, considering that the hydrogen coverage must decrease with increasing temperature at the same $p\left(\mathrm{H}_{2}\right)$. The effect of $p(\mathrm{H} 2)$ was studied at $513 \mathrm{~K}$. At $16 \mathrm{kPa}$, the values of $2 \mathrm{MP} / \mathrm{nH}$ were $\sim 2.5$ on $\mathbf{P t}$ and $\sim 4$ on $\mathbf{R h}$, with the value of $\sim 3$ on Rh-Pt in between. Increasing the hydrogen pressure up to $64 \mathrm{kPa}$ increased this ratio up to $\sim 6$ on Pt and $\mathbf{R h}-\mathbf{P t}$ and to $\sim 5.5$ on $\mathbf{R h}$. This confirms that metal sur faces containing ample hydrogen are favorable for "selective" ring opening on $\mathrm{Pt}, \mathrm{Rh}$, and a combination of the two.

\subsubsection{Effects of pretreatments}

EM showed randomly distributed $\mathrm{Rh}$ enrichment on surface areas, meaning that we did not reach this state initially, even though complete miscibility was reported on the Rh-Pt pair [35]. This was approached gradually during subsequent treatments (Fig. 4, Table 1). This may be due in
Table 4: Temperature and $\mathrm{H}_{2}$ pressure dependence of the conversion of MCP on $\mathbf{R h}-\mathbf{P t}$ after the four pretreatments

\begin{tabular}{lllll}
\hline & \multicolumn{3}{l}{ Conversion $(\%)$} \\
\cline { 2 - 5 } Pretreatments & $\mathbf{L T H}$ & $\mathbf{O}_{\mathbf{2}}$ & $\mathbf{M T H}_{\mathbf{2}}$ & $\mathbf{H T H}_{\mathbf{2}}$ \\
\hline Temperature $(\mathrm{K})$ & & & & \\
468 & 0.4 & 0.5 & 0.2 & 0.2 \\
483 & 0.7 & 0.8 & 0.2 & 0.3 \\
513 & 0.8 & 2.1 & 0.7 & 0.8 \\
543 & 0.7 & 2.3 & 0.9 & 1.3 \\
573 & - & 1.3 & 0.7 & 1.1 \\
603 & - & - & 0.9 & 0.9 \\
$\mathrm{H}_{2}$ pressure $(\mathrm{kPa})$ & & & & \\
8 & 0.7 & 0.4 & 0.3 & 0.3 \\
16 & 1.7 & 1.6 & 1.0 & 0.8 \\
32 & 3.6 & 1.9 & 1.5 & 1.0 \\
48 & 3.8 & 2.4 & 1.6 & 1.2 \\
64 & 2.9 & 1.8 & 1.4 & 1.1 \\
\hline
\end{tabular}

part to the fact that a considerable fraction of Rh was oxidized, and reduction of $\mathrm{Rh}$ oxide may have promoted its mixing with Pt (Fig. 5).

Conversions and selectivities were checked after the four pretreatments. The temperature effect was studied at one selected feed composition. $p(\mathrm{MCP}): p\left(\mathrm{H}_{2}\right)=1.3: 16$ $\mathrm{kPa}$, and the hydrogen pressure effect was investigated at $513 \mathrm{~K}$. The top part of Table 4 depicts the conversion values as a function of temperature. The highest activity can be seen after $\mathbf{O}_{2}$ treatment when the percentage of surface carbon was the lowest (see Table 1). A similar phenomenon was reported by Gao and Schmidt [57], who observed an activity increase in ethane hydrogenolysis over six metal catalysts on $\mathrm{SiO}_{2}$ (mostly on $\mathrm{Rh}$ and $\mathrm{Ru}$ ) after $\mathrm{O}_{2}$ treatment. The explanation that they suggested for this was oxidation of the metal to form a contiguous oxide layer, as demonstrated by XPS [11]. This formed small particles when reduced during subsequent hydrogen treatment, in which the abundant low-coordination sites were rather active in $\mathrm{C}-\mathrm{C}$ bond breaking. A massive oxidation of Rh also occurred in our case (Fig. 5), and although separate small particles could not be formed during their reduction of an unsupported system, it could have been reconstructed to structures exposing lowcoordination sites. The selectivity plots (Figs. 8 and 9) show that these sites promote both the "milder" $\mathrm{C}-\mathrm{C}$ bond rupture to $\mathrm{ROP}$ and the subsequent more "aggressive" reaction to form $<\mathrm{C}_{6}$ fragments.

A different behavior, analogous to that reported by Gao and Schmidt [57], was observed in the first run with Rh-Pt kept in air (see the curves for $<\mathrm{C}_{6}$ and ROP selectivities at $468 \mathrm{~K}$ in Figs. 7a and 7b). XPS confirmed that Rh oxide accumulated during weeks of storage at room temperature (see the Rh $3 d_{5 / 2}$ of the "as is" sample in Fig. 4). The high fragment selectivity ( 30\%; see Fig. 8b) observed in the first catalytic run with no pretreatment may indicate that the state of oxidized $\mathrm{Rh}$ allowed the formation of structures with low-coordination metallic sites on reduction on the Pt matrix, even if the formation of separate particles (as reported for silica [11,57]) may not have been possible. The presence of $\mathrm{H}_{2}$ during the catalytic run and the second treatment eliminated these sites (cf. mixing of reduced $\mathrm{Rh}$ with Pt; see Fig. 5), accordingly dropping the $<\mathrm{C}_{6}$ selectivity to $<10 \%$. 

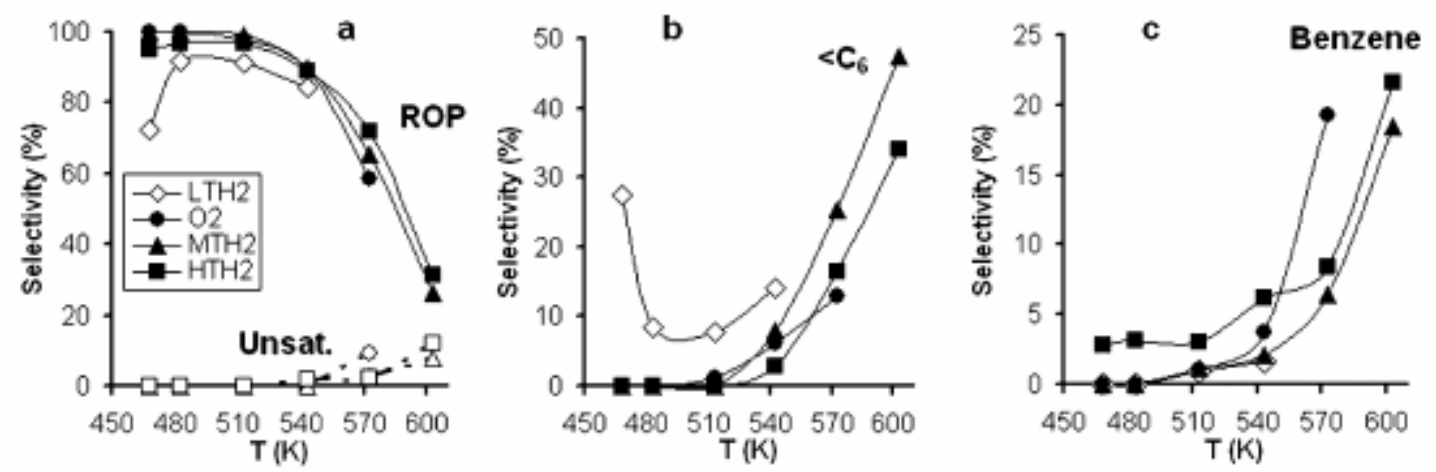

Figure 8: (a) Selectivity of ring opening (curves in the upper region) and unsaturated products (curves close to the abscissa); (b) fragments; (c) benzene on Rh-Pt after the four pretreatments as a function of temperature at $p(\mathrm{MCP}): p\left(\mathrm{H}_{2}\right)=1.3: 16 \mathrm{kPa}, t=5$ $\min$.
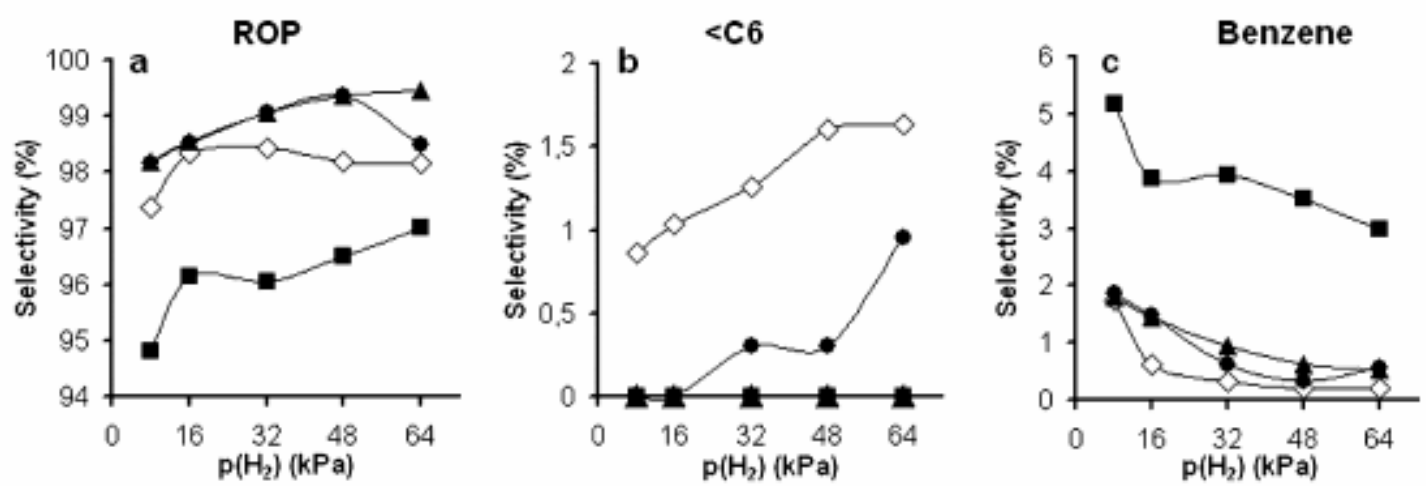

Figure 9: (a) Selectivity of ring opening products; (b) fragments; (c) benzene on $\mathbf{R h}-\mathbf{P t}$ after the four pretreatments as a function of hydrogen pressure at $513 \mathrm{~K}, t=5 \mathrm{~min}$.

Fragment formation was more pronounced with increasing temperatures with parallel decreases in ROP selectivities. The formation of unsaturated products (Fig. 8a) and benzene (Fig. 8c) was increased at high temperatures. These products were insignificant or missing after $\mathbf{L} \mathbf{T H}$. The high aromatization selectivity at the expense of fragmentation after $\mathbf{O}_{2}$ treatment, with the lowest carbon impurities present (cf. Table 1), is worth mentioning. The dramatic effect of the first regeneration of the fresh catalyst on the relative amounts of ROP and fragments can be seen here as well $\left(\mathbf{L} \mathbf{T H} \mathbf{H}_{\mathbf{2}}\right.$ ). Nevertheless, this sample produced the highest fragment selectivity, showing a more Rh-type behavior that was lost after further treatments, in agreement with the Rh peak shown on XPS (Fig. 4). On the other hand, the lower fragmentation selectivity after $\mathbf{H T H}_{\mathbf{2}}$ was in agreement with its Pt enrichment. This also was manifested in the augmented benzene selectivities (Figs. 8 and 9). The structure of $\mathbf{R h}-\mathbf{P t}$ may be close to the model shown for small amounts of Rh in the Pt matrix [58], namely that individual $\mathrm{Rh}$ atoms or small $\mathrm{Rh}$ islands may be present in the surface or near-surface layers of Pt. (The low Pd content in the system described in [58] did not seem to influence the distribution of Rh.) Segregation of the small grains into Pt and Pt-Rh alloy with 40\% Rh [59] is not likely here, due to the very small Rh content here.

The customary maximum values of the overall conversion have been observed as a function of the hydrogen pressure (Table 4, lower part). Consecutive pretreatments decreased the amount of conversion. This may be another indication of a possible particle aggregation, and this phenomenon had an opposite effect than formation of lowcoordination sites [57] on reduction after $\mathrm{O}_{2}$ treatment (Figs. 8 and 9). Figs. 9a-9c illustrate that under the selected conditions (513 K), the selectivity of ROP was 95-98\%, with the remainder consisting mostly of fragments $\left(\mathbf{L T H}_{\mathbf{2}}\right.$ and $\mathbf{O}_{2}$ ) or benzene $\left(\mathbf{H T H}_{\mathbf{2}}\right.$ and also $\left.\mathbf{L} \mathbf{T H}_{\mathbf{2}}\right)$. No fragments were observed in the latter two cases. The temperature selected was too low for olefin formation (cf. Fig. 8a).

Ring opening was "selective" in each case; that is, the $2 \mathrm{MP} / \mathrm{nH}$ ratio exceeded the statistical value of 1 , as has been reported for most metal catalysts [6,33,49-51,53,55]. This reaction purportedly began with the dissociation of the weakest $\mathrm{C}-\mathrm{H}$ bond at the tertiary $\mathrm{C}$-atom on one active site of a surface saturated with hydrogen [49]. The atomic diameter of both $\mathrm{Pt}$ and $\mathrm{Rh}$ made it possible for a second active site to interact with the two di-secondary $\mathrm{C}-\mathrm{C}$ bonds of the ring, producing 2MP and 3MP [33]. Formation of the latter was preferred on $\mathrm{Rh}$ of smaller atomic diameter (2MP/3MP < 2; cf. Table 5). In this respect, Rh-Pt exhibited Rh-like character at higher temperatures. Most "selective" ring opening occurred after $\mathbf{L} \mathbf{T H}_{2}$, at which point no hexane could be detected (Table 5). Fragments were reportedly formed as secondary products first from the $2 \mathrm{MP}$ primary product $[33,43,44]$. This may a cause of the de 
Table 5: Ratio of various ring opening products on $\mathbf{P t}, \mathbf{R h}-$ $\mathbf{P t}$, and $\mathbf{P t}$ in the "as prepared" state $(\mathbf{L T H})$ and on $\mathbf{R h}-\mathbf{P t}$ after pretreatment at $673 \mathrm{~K}\left(\mathbf{H T H}_{2}\right)$. $p(\mathrm{MCP}): p\left(\mathrm{H}_{2}\right)=$ $1.3: 16 \mathrm{kPa}$

\begin{tabular}{|c|c|c|c|c|c|}
\hline \multirow[b]{2}{*}{ Catalyst } & \multicolumn{5}{|c|}{$2 \mathrm{MP} / \mathrm{nH}$} \\
\hline & $\overline{\mathbf{P t}}$ & Rh-Pt LTH $_{2}$ & $\mathrm{Rh}-\mathrm{Pt} \mathrm{O}_{2}$ & $\mathrm{Rh}-\mathrm{Pt} \mathrm{HTH}_{2}$ & Rh \\
\hline \multicolumn{6}{|c|}{ (a) 2-Methylpentane to hexane } \\
\hline \multicolumn{6}{|c|}{ Temperature (K) } \\
\hline 468 & & a & s & 2.9 & 6.4 \\
\hline 483 & 14.0 & a & a & 4.3 & 5.0 \\
\hline 498 & & a & s & & 4.4 \\
\hline 513 & 7.4 & a & a & 5.7 & 4.1 \\
\hline 543 & 4.0 & a & a & 4.4 & \\
\hline 573 & 2.4 & & s & 2.1 & \\
\hline 603 & 1.5 & & & 1.5 & \\
\hline \multicolumn{6}{|c|}{ (b) 2-Methylpentane to 3-methylpentane } \\
\hline \multicolumn{6}{|c|}{ Temperature $(\mathrm{K})$} \\
\hline 468 & & 2.7 & 3.0 & 3.1 & 1.4 \\
\hline 483 & 2.9 & 2.7 & 3.0 & 3.0 & 1.4 \\
\hline 498 & & & & & 1.4 \\
\hline 513 & 2.7 & 2.6 & 2.6 & 2.7 & 1.2 \\
\hline 543 & 2.2 & 2.2 & 2.2 & 2.2 & \\
\hline 573 & 1.7 & & 1.7 & 1.8 & \\
\hline 603 & 1.5 & & & 1.6 & \\
\hline
\end{tabular}

creasing 2MP/nH ratio (Table 5). Another cause may be the fact that formation of more $1-\mathrm{MCP}=$ was concomitant with lower 2MP/nH ratios [47]. Keep in mind that both hexane and $1 \mathrm{MCP}=$ involve interaction of the catalyst with the $\mathrm{C}-$ $\mathrm{C}$ bond in the vicinity of the tertiary $\mathrm{C}$ atom (position "a”). The statements on the changes of the ROP product ratios are valid for both Pt and Rh.

\section{Conclusion}

Underpotential deposition of $\mathrm{Rh}$ on to the surface of a Pt black catalyst was applied to prepare a bimetallic $\mathbf{R h}-$ Pt catalyst. This $\mathbf{R h}-\mathbf{P t}$ was characterized by CV, XPS, and TEM. Absolute surface-sensitive CV showed 15-20\% $\mathrm{Rh}$ on the surface. EM indicated that this procedure did not

\section{References}

[1] V. Ponec, G.C. Bond, in: Catalysis by Metals and Alloys Studies in Surface Science and Catalysis, vol. 85, Elsevier, Amsterdam, 1995.

[2] G.C. Bond, Metal-Catalyzed Reactions of Hydrocarbons, Springer, New York, 2005.

[3] L. Pirault-Roy, M. Guérin, F. Maire, P. Marécot, J. Barbier, Appl. Catal. A 199 (2000) 109.

[4] Z. Hu, F.M. Allen, C.Z. Wan, R.M. Heck, J.J. Steger, R.E. Lakis, C.E. Lyman, J. Catal. 174 (1998) 13.

[5] Z. Paál, P. Tétényi, in: G.C. Bond, G. Webb (Eds.), Catalysis, Specialist Periodical Report, vol. 5, The Royal Soc. Chem., London, 1982, p. 80.

[6] Z. Paál, P. Tétényi, Nature 267 (1977) 234.

[7] Z. Karpinski, J.K.A. Clarke, J. Chem. Soc. Faraday Trans. 1 (71) (1975) 893.

[8] Ref. [2], Section 14.5.5.

[9] J. Siera, F.C.M.J.M. van Delft, A.D. van Langeveld, B.E. Nieuwenhuys, Surf. Sci. 263 (1992) 435. change the morphology of Pt, which appeared as an aggregate of Pt crystallites of $10-15 \mathrm{~nm}$. Rh appeared on the surface (Fig. 2b). It did not form either individual crystallite or a continuous overlayer. XPS, giving a signal from a greater depth of information, indicated the presence of 2$2.5 \% \mathrm{Rh}$, along with adventitious carbon and oxygen impurities. Oxygen was present in a chemisorbed form on Pt, and in turn a large fraction of Rh was in the oxidized state $\left(\mathrm{Rh}^{2+}\right.$ or even $\left.\mathrm{Rh}^{3+}\right)$. The main products of the test reactions with MCP in the temperature range 468-603 K were ROPs (the $\mathrm{C}_{6}$ alkanes $2 \mathrm{MP}, 3 \mathrm{MP}$, and $\mathrm{nH}$ ) and $<\mathrm{C}_{6}$ fragments, the amount of which increased markedly at higher temperature. Benzene and methylcyclopentene also appeared at higher temperatures. Ring opening was selective on all three metals, producing much more $2 \mathrm{MP}$ than $\mathrm{nH}$. In most cases, the 2MP/3MP ratio was greater than the statistical value of 2 . Treatment with $\mathrm{H} 2$ at 473,603 , and $673 \mathrm{~K}$ removed most oxygen impurities, whereas $\mathrm{O}_{2}$ treatment removed the most carbon. These subsequent treatments also caused reconstruction of the catalyst, with less Rh remaining on the surface after these treatments. Rh oxidized by $\mathrm{O}_{2}$ at $573 \mathrm{~K}$ was reduced by $\mathrm{H}_{2}$ at $603 \mathrm{~K}$, but the reduced $\mathrm{Rh}$ apparently migrated into the bulk. In agreement with the XPS findings, the catalytic selectivities corresponded to these structural and composition changes. We showed-and this may be the main point of the present work - that adding even a relatively small amount of $\mathrm{Rh}$ to Pt created a $\mathbf{R h}-\mathbf{P t}$ catalyst with different properties than those of its components, behaving as a true bimetallic catalyst with activity and selectivity values between those of $\mathbf{P t}$ and $\mathbf{R h}$.

\section{Acknowledgement}

A. Wootsch received financial support from a Grant Bolyai from the Hungarian Academy of Sciences.

[10] N. Savargaonkar, B.C. Khanra, M. Pruski, T.S. King, J. Catal. 162 (1996) 277.

[11] T. Wang, L.D. Schmidt, J. Catal. 71 (1981) 411.

[12] A.V. Kalinkin, A.V. Pashos, R.I. Kvon, React. Kinet. Catal. Lett. 72 (2001) 163.

[13] A. Baraldi, D. Giacomello, L. Rumiz, M. Moretuzzo, S. Lizzit, F. Buatier de Mongeot, G. Paolucci, G. Comelli, R. Rosei, B.E. Nieuwenhuys, U. Valbusa, M.P. Kiskinova, J. Am. Chem. Soc. 127 (2005) 5671.

[14] Ref. [1], Section 4.3.3.

[15] A. Suopanki, R. Polvinen, M. Valden, M. Härkönen, Catal. Today 100 (2005) 327.

[16] F.C.M.J.M. van Delft, A.D. van Langeveld, B.E. Nieuwenhuys, Surf. Sci. 189/190 (1987) 1129.

[17] S. Szabó, F. Nagy, D. Móger, Acta Chim. Acad. Sci. Hung. 93 (1977) 33.

[18] S. Szabó, Int. Rev. Phys. Chem. 10 (1991) 207. 
[19] J. Barbier, in: G. Ertl, H. Knözinger, J. Weitkamp (Eds.), Preparation of Solid Catalysts, Wiley-WCH, Weinheim, 1999, p. 526.

[20] I. Bakos, S. Szabó, J. Electroanal. Chem. 547 (2003) 103.

[21] N. Gy"orffy, A. Wootsch, S. Szabó, I. Bakos, L. Toth, Z. Paál, Top. Catal., doi: 10.1007/s11244-007-0315-7, in press.

[22] D. Teschner, Z. Paál, React. Kinet. Catal. Lett. 68 (1999) 25.

[23] Z. Paál, A. Wootsch, R. Schlögl, U. Wild, Appl. Catal. A 282 (2005) 135.

[24] Z. Paál, Zh. Zhan, Langmuir 13 (1997) 3752.

[25] Z. Paál, U. Wild, A. Wootsch, J. Find, R. Schlögl, Phys. Chem. Chem. Phys. 3 (2001) 2148.

[26] A. Wootsch, Z. Paál, S. Szabó, I. Bakos, H. Sauer, U. Wild, R. Schlögl, Appl. Catal. A 309 (2006) 1.

[27] A. Wootsch, Z. Paál, J. Catal. 205 (2002) 86.

[28] U. Wild, D. Teschner, R. Schlögl, Z. Paál, Catal. Lett. 67 (2000) 93.

[29] Z. Paál, K. Matusek, M. Muhler, Appl. Catal. A Gen. 149 (1997) 113.

[30] J. Find, Z. Paál, R. Schlögl, U. Wild, Catal. Lett. 65 (2000) 19.

[31] Z. Paál, R. Schlögl, G. Ertl, Catal. Lett. 12 (1992) 331.

[32] D. Briggs, M.P. Seah (Eds.), Practical Surface Analysis, vol. 1, Wiley, Chichester, 1990, Appendix 6, p. 635.

[33] D. Teschner, D. Duprez, Z. Paál, J. Mol. Catal. A (2002) 201.

[34] P.J. Lévy, V. Pitchon, V. Perrichon, M. Primet, M. Chevrier, C. Gauthier, J. Catal. 178 (1998) 363.

[35] B. Kolb, S. Müller, D.B. Botts, G.L.W. Hart, Phys. Rev. B 74 (2006) 144206.

[36] Z. Paál, R.R. Schlögl, Surf. Interface Anal. 19 (1992) 524.

[37] A.M. Venezia, Catal. Today 77 (2003) 359.

[38] B. Veisz, L. Tóth, D. Teschner, Z. Paál, N. Györffy, U. Wild, R. Schlögl, J. Mol. Catal. A 238 (2005) 56.
[39] U. Wild, D. Teschner, Z. Paál, R. Schlögl, Catal. Lett. 67 (2000) 93.

[40] Z. Paál, Zh. Zhan, E. Fülöp, B. Tesche, J. Catal. 156 (1995) 19.

[41] K.S. Kim, N. Winograd, R.E. Davis, J. Am. Chem. Soc. 93 (1971) 6296.

[42] N.M. Rodriguez, P.E. Anderson, A.Wootsch, U.Wild, R. Schlögl, Z. Paál, J. Catal. 197 (2001) 365.

[43] D. Teschner, Z. Paál, D. Duprez, Catal. Today 65 (2001) 185.

[44] D. Teschner, K. Matusek, D. Duprez, J. Catal. 192 (2000) 335.

[45] M. Chamam, A.Wootsch, L. Pirault-Roy, I. Boghian, Z. Paál, Catal. Commun. 8 (2007) 686.

[46] Ref. [2], Section 13.2.4 and references therein.

[47] A. Wootsch, Z. Paál, J. Catal. 185 (1999) 192.

[48] M. Temkin, Acta Physicochim. URSS 3 (1935) 312.

[49] Z. Paál, in: I.T. Horváth (Ed.), Encyclopaedia of Catalysis, vol. 6, Wiley, New York, 2002, p. 116.

[50] Z. Paál, Catal. Today 2 (1988) 595.

[51] H. Zimmer, Z. Paál, J. Mol. Catal. 51 (1989) 261.

[52] Z. Paál, G. Székely, P. Tétényi, J. Catal. 58 (1979) 108.

[53] G. Maire, G. Plouidy, J.C. Prudhomme, F.G. Gault, J. Catal. 4 (1965) 556.

[54] B.H. Davis, Catal. Today 53 (1999) 443.

[55] O.V. Bragin, Z. Karpinski, K. Matusek, Z. Paál, P. Tétényi, J. Catal. 56 (1979) 219.

[56] H. Glassl, K. Hayek, R. Kramer, J. Catal. 68 (1981) 397.

[57] S. Gao, L.D. Schmidt, J. Catal. 115 (1989) 356.

[58] Y. Chen, S. Liao, H. Deng, Appl. Surf. Sci. 252 (2007) 6074.

[59] T.P. Chojnacki, L.D. Schmidt, J. Catal. 115 (1989) 473. 